\title{
HIDROLISIS SELULOSA DARI SEKAM PADI (Oryza sativa) MENJADI GLUKOSA DENGAN KATALIS ARANG TERSULFONASI
}

\section{[Cellulose Hydrolysis from Rice Husk (Oryza sativa) Into Glucosa With Sulfonated Charcoal Catalyst]}

\author{
Adeks Pramana $^{{ }^{\star}}$, Abd. Rahman Razak ${ }^{1}$, Prismawiryanti ${ }^{1}$ \\ 1) Jurusan Kimia Fakultas MIPA, Universitas Tadulako \\ Jl. Soekarno Hatta Km.9, Kampus Bumi Tadulako Tondo Palu, Telp. 0451- 422611
}

Diterima 20 Mei 2016, Disetujui 8 Agustus 2016

\begin{abstract}
Cellulose hydrolysis from rice husk (Oryza sativa) into glucose with sulfonated charcoal catalyst was conducted. The aim of this research was to determine sulfuric acid concentration and contact time on the sulfonation process of charcoal which would produce the highest glucose rendement from cellulose hydrolysis of rice husk. Sulfuric acid concentrations in this experiment were 8,10 , and $12 \mathrm{~N}$ with variation of contact time of $4,6,8,10$ and 12 hours respectively. Rice husk was delignified with $\mathrm{NaOH} 10 \%$ to produce cellulose which was hydrolyzed by sulfonated charcoal catalyst. Hydrolysis reaction with the ratio cellulose/aquadest 1:25 (w/v) was conducted in autoclave with temperature 130 ${ }^{\circ} \mathrm{C}$ for 3 hours. The result showed that $8 \mathrm{~N}$ concentration of sulfuric acid and 12 hours of contact time produced the highest glucose rendement $17,9 \%$.
\end{abstract}

Keywords : rice husks, cellulose, glucose, sulfonated charcoal.

\begin{abstract}
ABSTRAK
Telah dilakukan penelitian tentang hidrolisis selulosa dari sekam padi (Oryza sativa) menjadi glukosa dengan katalis arang tersulfonasi. Penelitian ini bertujuan untuk menentukan konsentrasi asam sulfonat dan waktu kontak dalam proses sulfonasi arang yang menghasilkan rendemen glukosa tertinggi hasil hidrolisis selulosa dari sekam padi. Konsentrasi asam sulfonat yang digunakan adalah 8, 10 dan $12 \mathrm{~N}$, dengan variasi waktu kontak 4, 6, 8, 10 dan 12 jam. Penelitian ini diawali dengan proses delignifikasi sekam padi menggunakan larutan $\mathrm{NaOH} 10 \%$, selanjutnya selulosa yang diperoleh di hidrolisis menggunakan katalis arang tersulfonasi. Reaksi hidrolisis dengan perbandingan selulosa/aquades 1:25 (w/v) dilakukan dalam autoklaf pada suhu $130^{\circ} \mathrm{C}$ selama 3 jam. Hasil penelitian menunjukan konsentrasi asam sulfonat dan waktu kontak yang menghasilkan rendemen glukosa tertinggi adalah $8 \mathrm{~N}$ dan 12 jam dengan rendemen glukosa sebesar 17,9\%.
\end{abstract}

Kata kunci : sekam padi, selulosa, glukosa, arang tersulfonasi. 


\section{LATAR BELAKANG}

Indonesia merupakan penghasil biomassa yang cukup melimpah, baik yang berasal dari limbah pertanian, limbah perkebunan, limbah industri maupun limbah rumah tangga, contohnya tandan kosong sawit, tongkol jagung, bagas tebu, bagas sorgum manis, dan sekam padi (Oktaveni, 2011). Sekam padi adalah salah satu sumber biomassa yang sangat potensial, dimana pemanfaatannya masih sangat terbatas, yakni sebagai bahan pakan ternak, media pertumbuhan jamur merang dan pupuk kompos. Sekam padi mempunyai kandungan lignoselulosa yang tinggi, yakni terdiri atas selulosa (31,4 $36,3 \%)$, hemiselulosa $(2,9-11,8 \%)$, dan lignin $(9,5-18,4 \%)$. Limbah sekam padi dapat dimanfaatkan sebagai sumber selulosa untuk produksi glukosa (Champagne dan Elaine, 2004).

Glukosa dapat diproduksi dari selulosa melalui proses hidrolisis yakni pemecahan suatu molekul karena pengikatan air, menghasilkan molekulmolekul yang lebih kecil. Hidrolisis bisa dilakukan secara kimiawi. Faktor-faktor yang mempengaruhi hidrolisis secara kimia adalah konsentrasi asam, suhu dan lama hidrolisis. Pada kondisi normal, reaksi yang terjadi antara air dengan komponen organik sangat lambat sehingga diperlukan adanya penambahan katalis homogen dan katalis heterogen (Amelia dkk., 2013).

Katalis homogen seperti larutan asam pada proses hidrolisis yang dilakukan
Hamerlick dkk., (2005) menghasilkan kadar glukosa yang tinggi sekitar 90\%, akan tetapi dari hasil penelitian lebih lanjut yang dilakukan oleh Grethlein (1984) pada hidrolisis dengan menggunakan asam pada konsentrasi tinggi, glukosa yang dihasilkan terdegradasi menjadi senyawasenyawa furfural. Untuk itu, diperlukan katalis yang tidak mendegradasi glukosa. Penggunaan katalis heterogen seperti arang aktif tersulfonasi merupakan alternatif untuk menghindari terjadinya degradasi glukosa sebagaimana dilaporkan oleh Anggraeni (2013). Jumlah katalis arang aktif tersulfonasi sangat berpengaruh signifikan terhadap perubahan reaksi selulosa menjadi glukosa (Anggoro dkk., 2013), tetapi dalam proses hidrolisis terjadi hambatan oleh adanya lignin dan kristalin yang berfungsi sebagai pelindung selulosa (Judoamidjojo dkk., 1989).

\section{METODE PENELITIAN}

\section{Bahan dan Peralatan}

Peralatan yang digunakan dalam penelitian ini terdiri dari, magnetik stirer, oven, ayakan 60 mesh, lumpang dan alu, autoclave, tanur, UV-VIS HITACHI U-2810 model : 122-000, FTIR shimadzu IRPrestige 21, ultra mill centrifugal, kertas saring Whatman No.41, kertas $\mathrm{pH}$, kapas dan peralatan gelas yang umum digunakan dalam laboratorium.

Bahan dasar yang digunakan dalam penelitian ini adalah sekam padi, arang 
aktif, $\mathrm{H}_{2} \mathrm{SO}_{4} 8 ; 10 ; 12 \mathrm{~N}, \mathrm{NaOH} 10 \%$, dinitrosalisilat (DNS) dan akuadest.

\section{Prosedur Penelitian}

\section{Pembuatan Katalis Arang Tersulfonasi (Anggraeni, 2013)}

$\mathrm{Ke}$ dalam erlenmeyer $250 \mathrm{~mL}$ dimasukan $10 \mathrm{~g}$ arang, ditambahkan asam sulfonat (8, 10, dan 12N). Kemudian dilakukan pengadukan selama $(4,6,10$ dan 12 jam) pada suhu $45^{\circ} \mathrm{C}$.

\section{Delignifikasi Sekam Padi (Pertiwi, 2013)}

Serbuk sekam padi diambil sebanyak $10 \mathrm{~g}$ di aduk dalam larutan $\mathrm{NaOH} 10 \%$, larutan yang ditambahkan memiliki perbandingan volume dengan $\mathrm{H}_{2} \mathrm{O}$ sebesar 1:25 (b/v). Selanjutnya larutan dipanaskan pada suhu $55^{\circ} \mathrm{C}$ selama 90 menit. Residu diambil dengan cara disaring menggunakan kertas saring dan dinetralkan melalui pembilasan menggunakan akuades.

\section{Proses Hidrolisis Hidrolisis Selulosa Sekam Padi (Pertiwi, 2013).}

$\mathrm{Ke}$ dalam erlenmeyer $250 \mathrm{~mL}$ dimasukan $0,8 \quad \mathrm{~g}$ selulosa hasil delignifikasi, kemudian ditambahkan masing-masing dengan 1,2 $\mathrm{g}$ arang tersulfonasi dan dilakukan penambahan akuades dengan perbandingan 1:25 (b/v). Campuran dimasukan kedalam autoklaf pada suhu $130^{\circ} \mathrm{C}$ selama 3 jam, dilakukan penyaringan. Filtrat kemudian dinetralkan menggunakan $\mathrm{NaOH} 10 \%$. Kadar glukosa ditentukan dalam filtrat ditentukan dengan metode DNS.

\section{Penentuan Kadar Glukosa dengan Metode DNS}

Sebanyak $1 \mathrm{~mL}$ filtrat hasil hidrolisis dimasukkan ke dalam tabung reaksi dan ditambahkan dengan $3 \mathrm{~mL}$ pereaksi DNS, selanjutnya dipanaskan pada penangas air mendidih selama 5 menit kemudian didinginkan pada suhu ruang, dilanjutkan dengan proses pengenceran bila larutan yang didapatkan sangat pekat. Larutan dipindahkan kedalam kuvet, absorbansi diukur pada panjang gelombang maksimum $550 \mathrm{~nm}$, selanjutnya bila larutan didapatkan sangat pekat dilanjutkan dengan proses pengenceran. Kadar gula ditentukan dengan menggunakan persamaan regresi absorbansi larutan standar.

\section{HASIL DAN PEMBAHASAN}

\section{Arang Tersulfonasi}

Tahap sulfonasi arang diitujukan untuk memperluas ukuran permukaan sehinggan nantinya setelah dicampurkan kedalam larutan $\mathrm{H}_{2} \mathrm{SO}_{4}$ dengan waktu dan suhu yang telah ditetapkan dimungkinkan akan di dapatkan struktur morfologi yang lebih terbuka yang nantinya reaktan (selulosa) masuk ke permukaan katalis sehingga diharapkan bisa berinteraksi dengan gugus $\mathrm{H}^{+}$yang terikat dipermukaan.(Amelia dkk., 2013). Spektrum spektum FTIR arang hasil sulfonasi disajikan pada Gambar 1. 


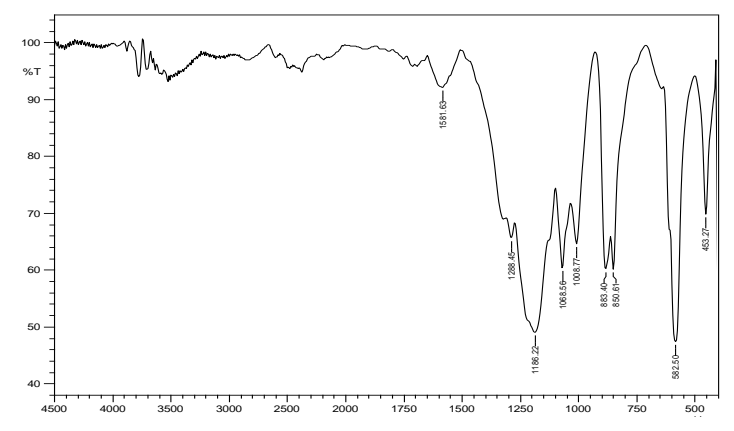

Gambar 1. Spektrum FTIR arang tersulfonasi

Terlihat perbedaan pita serapan yang kuat pada bilangan gelombang 1288,45 $\mathrm{cm}^{-1}$ dan pita serapan yang lemah pada kisaran bilangan gelombang $1750 \mathrm{~cm}^{-1}$. Hal ini senada dengan hasil penelitian Rispadi (2010), pita serapan pada bilangan gelombang $1750 \mathrm{~cm}^{-1}$ dan bilangan gelombang kisaran $1250 \mathrm{~cm}^{-1}$ tersebut menunjukkan keberadaan gugus sulfonat. Hal ini menujukkan bahwa sampel arang setelah sulfonasi mengandung gugus sulfonat sebagai bagian aktif (active site) dari katalis karbon aktif. Menurut hasil penelitian yang dilakukan oleh Amelia dkk., (2013) ukuran pori serbuk arang tempurung kelapa sebelum dan sesudah sulfonasi sangat jauh berbeda, dimana sebelum proses sulfonasi ukuran pori terlihat ukuran rongga kecil dan rapat, sedangkan setelah sulfonasi ukuran pori menjadi lebih besar dan terbuka. Mochida dkk., (2006) luas permukaan katalis ini diharapkan dapat berperan dalam interaksi pusat aktif dengan selulosa pada permukaan katalis.

\section{Glukosa Hasil Hidrolisis Berbagai Konsentrasi $\mathrm{H}_{2} \mathrm{SO}_{4}$}

Kadar glukosa hasil hidrolisis ditentukan oleh metode DNS dengan alat epektrofotometri UV-VIS pada panjang gelombang $550 \mathrm{~nm}$. Banyaknya DNS yang tereduksi sebanding dengan absorbansi. Hal ini terlihat pada kurva hubungan antara konsentrasi $\mathrm{H}_{2} \mathrm{SO}_{4}(\mathrm{~N})$ terhadap konsentrasi glukosa yang dihasilkan (ppm), yang disajikan pada gambar 2 .

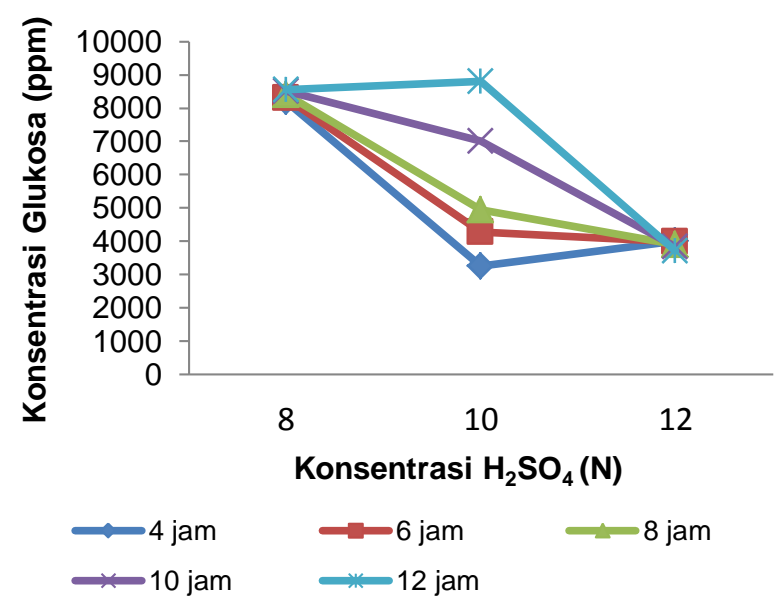

Gambar 2. Grafik hubungan antara Konsentrasi $\mathrm{H}_{2} \mathrm{SO}_{4}(\mathrm{~N})$ terhadap konsentrasi Glukosa (ppm).

Pada proses hidrolisis dengan katalis $\mathrm{H}_{2} \mathrm{SO}_{4} \quad 8 \quad \mathrm{~N}$ didapatkan rata-rata konsentrasi glukosa yang tinggi berkisar 8205 ppm, sedangkan untuk konsentrasi asam $10 \mathrm{~N}$ diperoleh konsentrasi glukosa yang lebih rendah pada waktu kontak 4, 6 , 8, 10 dan 12 jam, akan tetapi pada pada waktu 4 jam dengan konsentrasi asam $8 \mathrm{~N}$ diperoleh konsentrasi glukosa yang lebih tinggi. Pada konsentrasi $\mathrm{H}_{2} \mathrm{SO}_{4} 12 \mathrm{~N}$ kadar glukosa yang diperoleh lebih rendah dibandingkan dengan konsentrasi $\mathrm{H}_{2} \mathrm{SO}_{4}$ $8 \mathrm{~N}$ dan $10 \mathrm{~N}$ untuk semua perlakuan kecuali pada waktu kontak 4 jam. Hal ini dikarnakan jika reaksi atau kontak arang asam sulfonat yang memiliki normalitas 
yang terlalu tinggi terhadap permukaan katalis akan menyebabkan pori-pori katalis tertutup oleh sulfonat, sehingga menutup rongga pada arang tersebut (Amelia dkk., 2013).

\section{Glukosa Hasil Hidrolisis Berbagai Waktu Kontak}

Grafik hubungan antara waktu kontak terhadap konsentrasi glukosa disajikan pada gambar 3 .

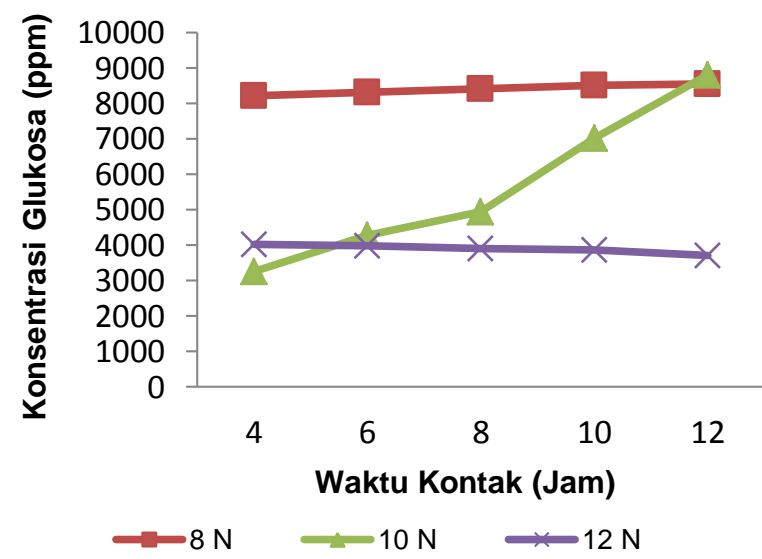

Gambar 3. Grafik hubungan antara waktu kontak (Jam) terhadap konsentrasi Glukosa (ppm).

Grafik d iatas menunjukkan pada waktu kontak 4 sampai 12 jam dengan konsentras sulfat 8 dan $10 \mathrm{~N}$ terjadi kenaikan konsentrasi glukosa, namun pada waktu kontak 4 sampai 12 jam dengan konsentras asam sulfat $12 \mathrm{~N}$ mengalami penurunan konsentrasi glukosa. Waktu kontak merupakan salah satu variabel yang mempengaruhi proses penyerapan yang merupakan lamanya kontak antara karbon dengan asam sulfat. Pada suatu proses adsorbsi proses akan terus berlangsung selama belum terjadinya suatu kesetimbangan. Dari data diatas terlihat bahwa pengaruh waktu berbanding lurus terhadap konsentrasi glukosa yang dihasilkan. Semakin lama waktu sulfonasi maka semakin banyak sulfonat yang terikat dipermukaan, akan tetapi pada perendaman arang dengan konsentrasi asam sulfat $12 \mathrm{~N}$ diperoleh konsentrasi glukosa yang lebih rendah dari pada konsentras asam sulfat $8 \mathrm{~N}$ dan $10 \mathrm{~N}$.

\section{KESIMPULAN}

Berdasarkan hasil penelitian yang diperoleh, disimpulkan bahwa konsentrasi $\mathrm{H}_{2} \mathrm{SO}_{4}$ pada proses sulfonasi arang yang menghasilkan konsentrasi glukosa tertinggi sebesar 8545 ppm adalah $8 \mathrm{~N}$. Waktu kontak terbaik pada proses perendaman arang dengan konsentrasi $\mathrm{H}_{2} \mathrm{SO}_{4}$ yang berbeda yang menghasilkan konsentrasi glukosa tertinggi sebesar 8805 ppm yaitu selama 12 jam. Konsentrasi $\mathrm{H}_{2} \mathrm{SO}_{4}$ dengan waktu kontak yang menghasilkan rendemen glukosa terbaik yakni pada konsentrasi $\mathrm{H}_{2} \mathrm{SO}_{4} 8 \mathrm{~N}$ dan waktu kontak 12 jam dengan rendemen glukosa sebesar $17,95 \%$.

\section{UCAPAN TERIMA KASIH}

Secara khusus peneliti menyampaikan ucapan terima kasih kepada sodara Syarifudin, S.Si., Laboran Jurusan Kimia, dan Himpunan Mahasiswa Kimia (HIMAKIM) FMIPA UNTAD.

\section{DAFTAR PUSTAKA}

Amelia R., Harlanto Padapotan, Purwanto. 2013. Pembuatan dan Karekterisasi Katalis Karbon 


Tersulfonasi Sebagai Katalis
Ramah Lingkungan Pada
Hidrolisis Biomassa.
Teknologi Kimia dan industri.
2(4):146-156.

Anggraeni $\mathrm{P}$, Zaqiyah Addarojah, Anggoro D.D. 2013. Hidrolisis Selulosa Enceng Gondok (Eichhornia crassipe) Menjadi glukosa dengan Katalis Arang Aktif tersulfonasi. Jurnal Teknologi Kimia dan industri. 2(3):63-69.

Anggoro D.D. 2013. Hidrolisis Selulosa Menjadi Glukosa Dengan Katalis Heterogen Arang Aktif Tersulfonasi. Jurnal Teknologi Kimia dan industri 2(4):34-36.

Casey P.J. 1980. Pulp and Paper, Chemistry and Chemical Technology Vol. 1 : Pulping and Paper Making. New York The Wiley Intersince Publisher Inc.

Champagne, Elaine T. 2004. Rice : Chemistry and Technology. Minnesota, USA: American Association of Cereal Chemist Inc. St. Paul,

Grethlein H. E. 1984. Pretreatment for Enhanced Hydrolysic of cellulosic Biomass. Biotechnology Advanced. 2(1): 43-62.

Hamerlick GW. Mj., Hooijdonk G, Faaij APC. 2005. Prospects for methanol from lignocellulose biomass: techno-economic performance as development progres. Scientifi report- NWS-E-2003-55. Utrecht University, Utrectht, The Netherlands: Departement of science, Technology and Society: 2003. 35pp.

Judoamidjojo, R.M., E.G Said dan L. Hartoto. 1989. Biokonversi. Bogor: PAU Bioteknologi IPB.

Mochida Isao, Ho Yoon Seong, dan Qiao Wenming. 2006. Catalysts in Syntheses and Carbon Precusors, J. Brazz. Chem. Soc. 17(6): 10591073.
Oktaveni. 2011. Ligin Terlarut Asam dan Delignifikasi pada Tahap Awal Proses Pulping Alkali. [Skripsi]. Bogor: Fakultas Kehutanan IPB.

Rispadi. 2010. Preparasi dan Karakterisasi Katalis Heterogen Arang Aktif Tersulfonasi Untuk Proses Hidrolisis Selulosa Menjadi Glukosa. Jurnal Fluida. 8(1):146156

Pertiwi R, 2013. Konversi glukosa hasil hidrolisis limbah sekam padi menjadi asam levulinat menggunakan katalis Mn/ZSM-5 mesopori. [Skripsi]. Depok: FMIPA UI. 